\title{
Counseling at a Seizure Clinic Does Not Ensure Disclosure to the Transportation Registry
}

\author{
Maria Siddiqi, Jeffrey Jirsch
}

\begin{abstract}
Background: The effectiveness of current self-reporting driving laws for medically-unfit potential seizure patients is unknown in Canada. We designed a prospective cohort study of patients' self-reporting practices to the local Transportation Registry (TR) and their driving behaviors following detailed counselling at a seizure clinic in a discretionary physician-reporting jurisdiction. Methods: Medically unfit drivers, referred to our seizure clinic, who had a valid driver's permit at the time of their episode of impaired consciousness were included. Patients' self-reporting and driving behaviours were assessed using a standardized interview prior to a neurologist's counseling and later at a follow-up visit. Results: Sixty three patients were included; $77 \%$ were diagnosed as having had a seizure at the time of their referral. Prior to their seizure clinic visit, 3/63 (5\%) had been counseled to self-report to the TR by a non-neurologist physician, and none had done so. Following a neurologist's documented counseling 34/63 (54\%) had self-reported themselves at the follow-up seizure clinic visit, and 53/63 (84\%) were not driving. Conclusion: This prospective study design is the first in North America to examine self-reporting rates for unfit drivers with a seizure disorder. Our findings suggest that self-reporting laws do not ensure high rates of selfreporting behaviors even when patients seen at a seizure clinic are appropriately counseled of their legal obligations. The rate of driving cessation appears greater than the rate of self-reporting to the TR among counseled patients.
\end{abstract}

RÉSUMÉ: Les conseils prodigués à une clinique d'épilepsie ne garantissent pas la déclaration au registre du Ministère des transports. Contexte : L'efficacité des lois actuelles sur la conduite automobile concernant l'auto-déclaration de la part de patients présentant potentiellement des crises convulsives est inconnue au Canada. Nous avons conçu une étude de cohorte prospective des pratiques d'auto déclaration des patients au registre du Ministère des transports et leur comportement de conduite après qu'ils aient reçu des conseils détaillés à une clinique d'épilepsie à accès rapide située dans une juridiction où la déclaration est laissée à la discrétion du médecin. Méthode : Les conducteurs inaptes pour des raisons médicales référés à notre clinique d'épilepsie à accès rapide et qui avaient un permis de conduire valide au moment où ils ont eu un trouble de la conscience ont été inclus dans l'étude. L'auto-déclaration par les patients et leur comportement de conduite ont été évalués au moyen d'une entrevue standardisée avant de recevoir des conseils d'un neurologue et lors d'une visite de suivi. Résultats : Soixante-trois patients ont été inclus dans l'étude. Chez 77\% des patients, un diagnostic de crise convulsive avait été posé au moment où ils avaient été référés à la clinique. Avant leur visite à la clinique d'épilepsie, 3/63 (5\%) avaient reçu le conseil de déclarer leur état au registre du Ministère des transports par un médecin qui n'était pas un neurologue et aucun ne l'avait fait. Après qu'ils aient reçu les conseils d'un neurologue, tel que consigné au dossier, 34/63 (54\%) avaient eux-mêmes divulgué leur état au registre du Ministère des transports lors de la visite de suivi à la clinique et 53/63 (84\%) ne conduisaient plus. Conclusion : Cette étude prospective est la première en Amérique du Nord à examiner les taux d'auto-déclaration des conducteurs inaptes à cause d'un problème de santé de nature épileptique. Selon nos constatations, les lois d'auto-déclaration ne garantissent pas des taux élevés d'auto-déclaration, même quand les patients examinés à une clinique d'épilepsie reçoivent des conseils appropriés concernant leurs obligations légales. Le taux d'arrêt de la conduite automobile semble supérieur au taux d'auto-déclaration au registre du Ministère des transports chez les patients qui ont reçu les conseils d'un neurologue.

Keywords: altered consciousness, discretionary physician reporting jurisdiction, epilepsy, driving, notification, self-disclosure, self-reporting, seizure, transportation registry

doi:10.1017/cjn.2015.41

Can J Neurol Sci. 2015; 42: 230-234

Transportation registries (TRs) across North America require reporting of patients with conditions that may impair the safe operation of a motor vehicle. Epileptic seizures and epilepsy are included prominently among such conditions. Reporting is performed either by the physician or the patient, depending on the jurisdiction. As opposed to mandatory physician-reporting jurisdictions, discretionary physician reporting jurisdictions rely solely on patients self-reporting their medical conditions to local TRs. Physicians providing accurate information regarding local driving and reporting laws is integral to the process of promoting self-reporting to TRs in discretionary physician-reporting jurisdictions. The benefit of disclosure to TRs has been shown to reduce motor vehicle accidents by almost half among medically unfit drivers. ${ }^{1}$

From the Department of Medicine, Division of Neurology, University of Alberta, Canada. Correspondence to: Jeffrey Jirsch, Department of Medicine, Division of Neurology, 2E3 WC Mackenzie Health Sciences Center, University of Alberta, Edmonton, AB, Canada T6G 2B7. Email: jeff.jirsch@ualberta.ca 
Self- reporting to TRs in discretionary physician-reporting jurisdictions is likely woefully inadequate, as even in mandatory physician-reporting jurisdictions medically unfit drivers are largely unknown to TRs. According to one large study in a mandatory physician reporting jurisdiction, among patients seen in a trauma center who were medically unfit to drive from a neurological cause only $21 \%$ were known to the local TR. ${ }^{2}$ The rate of reporting to the TR was approximately half in a discretionary physician-reporting province as compared to a mandatory physician reporting one. $^{3}$

The efficacy of self-reporting laws for seizure patients after they have been appropriately counseled by their physician to self-report is unknown in North America. Studies to date from discretionary reporting jurisdictions have found highly variable self-reporting rates of 4-60\% among epilepsy patients. ${ }^{4-10}$ These have been cross sectional and retrospective series, with little documentation regarding physician counseling of patients about their lawful responsibilities. A methodologically more rigorous longitudinal study design was performed almost 20 years back in the United Kingdom, and it was reported that $27 \%$ of potential seizure cases self-reported to their local registry. ${ }^{11}$ It is not clear whether self-reporting rates are equivalent in North America as compared to Europe or whether self-reporting rates have changed over the past two decades.

Alberta is included among the four Canadian provinces (representing approximately $50 \%$ of the country's population) with a discretionary physician reporting structure. In this study, we have tracked patients referred to a seizure clinic servicing Northern Alberta and who were provided with accurate information regarding self-reporting laws in the province. At a later follow-up visit we surveyed patients' interval self-reporting and driving behaviors.

\section{Materials ANd Methods}

A waiver of written consent was obtained following approval by the research ethics board of the University of Alberta. The study was designed as a prospective cohort assessment of driving and self-reporting practices in patients who had been seen at a seizure clinic in Northern Alberta.

\section{Local Driving and Reporting Regulations}

In Alberta, the Ministry of Transportation abides by the Canadian Counsel of Medical Transportation Authorities (CCMTA) consensus document among Canadian provinces to determine medical eligibility to hold a driver's permit. ${ }^{12}$ The document considers a single unprovoked seizure, epilepsy, seizures secondary to intoxication, as well as recurrent unexplained syncope as causes to restrict individuals' driver's permits. The Canadian Medical Association (CMA) driver's guide determining medical fitness to operate motor vehicle instructs physicians to withhold a determination of fitness for individuals holding standard driving permits for at least three months after a single unprovoked seizure or recurrent syncope and for six months after a diagnosis of epilepsy or after seizures induced by alcohol. ${ }^{13}$ In addition, Alberta's Traffic Safety Act (current as of June 2013) states that "A person who holds or applies for an operator's license shall immediately disclose to the Registrar a disease or disability that may be expected to interfere with the safe operation of a motor vehicle by the person."14

\section{Study Setting}

Patients were enrolled through the seizure clinic at the University of Alberta Hospital, (Edmonton, Alberta, Canada) from November 2011 to August 2013. The clinic operates in close liaison with Emergency Departments and Primary Care Networks in Northern Alberta, acting as a rapid referral avenue for potential seizure patients who are not actively being followed by a neurologist. The clinic is run by a fellowship-trained neurologist (epileptologist; JJ) in concert with an epilepsy nurse. In this clinic, patients are mostly seen within one week and rarely more than two weeks from the time of the initial referral to the clinic.

\section{Data Collection}

Data regarding individual demographics, diagnoses and source of referral were collected from the Electronic Medical Record (EMR). Other information was collected from two sources: Review of charts through EMR (Source 1) and a standardized questionnaire (Appendix 1) completed with the epilepsy nurse prior to the physician encounter at both visits (Source 2). Information regarding prior patient counseling by non-neurologist physicians regarding patients' duty to self-report and not drive was collected through Sources 1 and 2. Information regarding patient licensure status, driving, and self-reporting was collected through Source 2. Relying solely on patients' information for collection of certain data is a clear limitation of our methodology.

\section{Patient Selection}

Patients were included in the study if they: 1) held a valid driver's permit at the time of their initial seizure clinic visit, 2) were deemed medically unfit to drive secondary to an alteration in consciousness, 3) attended a follow-up visit to the seizure clinic, 4) had not been reported previously to the TR by a physician. Among 220 patients referred to the seizure clinic, 26 never attended their first appointment.

We excluded individuals for whom self-reporting to TR was not deemed necessary (131). These included individuals without a valid driver's permit (47), those who had been previously reported by the referral physician (6), individuals whose driving was not restricted at the initial seizure clinic visit (30), those who had their initial visit before the beginning of the study (20) and those who had not had attended a follow-up visit (28).

\section{Data Analysis}

We calculated the odds ratio (OR) for counseling about selfreporting to the TR to counseling about driving restriction by primary care physicians among different groups using chi square test.

\section{RESULTS}

The characteristics of 63 patients referred for an episode of transient alteration in consciousness to our seizure clinic are shown in the Table. The majority of patients referred to the clinic were seen following an unprovoked seizure without a diagnosis of epilepsy $(67 \%)$. Patients had initially presented most often to the Emergency Department (73\%), and less often to family physician offices (24\%) or specialist offices (3\%). Average delay from primary care encounter to initial seizure clinic visit was 


\section{Table: Patient characteristics}

\begin{tabular}{l|l}
\hline Total patients (number) & 63 \\
\hline Age (Median: years) & 36.7 \\
\hline Gender (Males: number and percentage) & $35(55.5 \%)$ \\
\hline Diagnostic category & $\mathrm{n}(\%)$ \\
\hline $\begin{array}{l}\text { - Seizure with alteration of consciousness not previously } \\
\text { diagnosed as epilepsy }\end{array}$ & $42(66.6)$ \\
\hline $\begin{array}{l}\text { - Seizure with alteration of consciousness previously } \\
\text { diagnosed as epilepsy }\end{array}$ & $6(9.5)$ \\
\hline $\begin{array}{l}\text { - Other episode of altered consciousness } \\
\text { b }\end{array}$ & $15(23.8)$ \\
\hline Source of referral & $\mathrm{n}(\%)$ \\
\hline - Emergency physician & $46(73)$ \\
\hline - Family physician & $15(23.8)$ \\
\hline - Specialist physician & \\
\hline
\end{tabular}

${ }^{\mathrm{a}}$ Unprovoked (33), alcohol provoked (5), drug abuse (4)

${ }^{\mathrm{b}}$ Syncope (8), unclear spell (7)

${ }^{\mathrm{c}}$ Neurosurgeon (1), psychiatrist (1)

11.6 days and from initial to follow-up seizure clinic visit was 102.7 days.

At the initial seizure clinic visit three $(5 \%)$ patients had been given instructions by their non-neurologist physicians regarding provincial reporting laws and $54(86 \%)$ had been counseled against driving. The odds of patients being counseled about their duty to self-report to TR at the time of the initial referral was significantly less than the odds of being counseled about driving (OR: 0.0083; 95\% CI: 0.0021-.0324). We did not find a statistically significant difference in the counseling rates between the three referral sources or reporting practices of patients by diagnosis and by median age ( $\leq$ or $>36.7$ years).

No patient had self- reported to the TR at the time of the initial seizure clinic visit. All 63 patients were provided clearly documented discussions regarding reporting laws in the province at the initial seizure clinic visit. Later at the second (i.e. follow-up) seizure clinic visit 34 (54\%) had self- reported to the local TR and $29(46 \%)$ remained unreported. Among different diagnostic categories, selfreporting rates to the TR were: seizure with alteration of consciousness not previously diagnosed as epilepsy 24/42 (60\%), seizure with alteration of consciousness previously diagnosed as epilepsy $2 / 6$ (33\%), and other episode of altered consciousness 7/15 $(47 \%)$. We did not find a statistically significant difference in the reporting rates of patients by gender (OR: 2.4 ; $95 \%$ CI: 0.8632 to 6.6732), diagnosis (seizures with alteration of consciousness vs. other episodes with alteration of consciousness) (OR: 2.1; 95\% CI: 0.6442 to 6.8457 ) and by median age ( $\leq$ or $>36.7$ yrs.); (OR: 0.66 ; 95\% CI: $0.2429-1.811)$. The rate of reporting was higher for patients referred from ER as compared to others, the difference being statistically significant (OR: 4.1; 95\% CI: 1.2296 to 13.632). Seventeen patients $(27 \%)$ were driving illegally prior to the initial seizure clinic visit, and $10(16 \%)$ at the second visit.

\section{DISCUSSION}

Contrary to mandatory physician reporting jurisdictions, in discretionary physician reporting jurisdictions the onus is primarily upon patients to self-report to TRs if they are medically unfit to drive. This study is the first to prospectively determine the rate of patient self-reporting to the TR after a neurologist has counseled the driver about self-reporting laws in a North American discretionary reporting jurisdiction. The main finding of our study is that even with clearly articulated specialist physician instructions of reporting laws provided to patients near the time of their seizures or other episodes of loss of consciousness, patient self-reporting in a discretionary physician reporting jurisdiction is low, and little over half. Comparing our results with the only other prospective study ascertaining the rates of self-reporting, ${ }^{11}$ we find that self-reporting rates may however be higher in North America than what have been previously reported almost twenty years ago in Europe.

One important factor contributing to non-reporting behaviors appears to be that patients are reluctant to follow reporting laws. In our study, we found that patients are more likely to be following driving restriction instructions $(86 \%)$ than self-reporting instructions $(54 \%)$ after physician counseling. In our informal discussions with patients, many feel that so long as they are not representing a hazard to others by continuing to drive following a seizure, they would rather self-regulate themselves than have a government agency monitor their behaviors. The common patient practice of self- imposing driving restrictions rather than reporting oneself to the TR has been previously eloquently explained by a patient with epilepsy. ${ }^{15}$ The essay summarizes common frustrations expressed by patients in a seizure clinic and includes worries about the ability of TRs to consider each individual's circumstances discriminately based at least in part upon patients' past driving performance, and the overarching power of TR advisory boards to make driver fitness decisions without reasonable avenues for patients to appeal or even partake in driver fitness decisions. Expected future bureaucratic delays in recovering a driver's permit due to the requirement of an annual medical report may be another reason for medically unfit drivers' reluctance to self-report to TRs. The loss of driving privileges is known to importantly impact quality of life for patients with epilepsy. ${ }^{16}$ Patients' desires to remain helpful family members, productive workers, mentally healthy individuals are understandable, and these are the patients' expected repercussions at the time of physician counseling about driver fitness and reporting laws. Presently, even within the more permissive administrative structure of a discretionary reporting jurisdiction, patients frequently hide their recent seizure history from their physicians due to fear of legal consequences related to present driving rules. 9,10

The great majority of the patients we studied do not have epilepsy, and most in our cohort have been referred to see a neurologist following a lone event. A single unprovoked seizure often does not recur ${ }^{11}$ and for patients when they decide whether to selfreport to the TR, their individual interpretation of event recurrence risk must be weighed against the certainty that self-reporting will result in their future surveillance by the TR. Even those diagnosed with incident epilepsy and started upon medication may have an unrealistic expectation that the therapy will render them seizure-free. Studies to date that have examined the rates of self-reporting among seizure patients have either only involved epilepsy patients or have not examined single seizure cases separately from epilepsy ones. ${ }^{8-11}$ It is our speculation that the likelihood for a patient to decide to selfreport may become incrementally strengthened after the individual has had further seizures in spite of medical efforts aimed to prevent 
those recurrences. One previous study found that $91 \%$ of medically unfit drivers with syncope were continuing to drive illegally even after physician counseling, additionally suggesting that the etiology of an individual's transient loss in consciousness could influence their driving-related behaviors. ${ }^{17}$

One further factor in patient non-reporting behaviors may be that non-neurologist physicians are frequently neglecting to provide patients with accurate information regarding reporting laws. We found that only $5 \%$ of patients had been provided with physician counseling that included education about reporting laws prior to referral to our seizure clinic. In the absence of education regarding reporting laws, it is therefore not surprising that we found that no patient had self-reported to the TR before being seen in our seizure clinic. Non-neurologist physicians may be ignorant of self-reporting laws and driver fitness guidelines resulting in absent or incomplete counseling of their patients; ${ }^{18-20}$ family physicians may be reticent to counsel about driving for fear of damaging a longstanding relationship with their patient; nonneurologist physicians may feel it is not their responsibility to tackle the matter assuming that the patient will be seen in followup by a neurologist. ${ }^{19-20}$ The failure of almost $12 \%$ of our patients to show up for their initial appointment with us at our seizure clinic makes it clear that non-neurologist reliance solely upon the neurologist to provide detailed driver counseling is misguided. Moreover, consistency between non-neurologist and neurologist driving discussions would in our view likely enhance patients' eventual compliance with driving and reporting regulations in the longer term.

We have found, in our study, an increase in self-reporting by patients between two clinic visits that may be attributable to the enhanced counseling received from a neurology specialist. This finding highlights the role of physicians in creating awareness regarding driving restrictions and reporting laws among their patients and how such counseling improves reporting practices as well as driving practices. In our seizure clinic, counseling of drivers about their duty to self-report includes a discussion about legal liability related to withholding medical information from the TR. Andermann noted improved compliance with driving laws when discussions included potentially adverse consequences in terms of insurance coverage when patients fail to report themselves. ${ }^{21}$ In our view there is considerable room for improvement in the rates of counseling about driving and reporting discussions by non-neurologist physicians, but potentially also inexperienced neurologists who do not frequently assess medically-unfit drivers. Quaglieri in $1977^{18}$ wrote that "the physician who deals with epileptics should know the laws of his particular [jurisdiction], inform his patients of their obligations under the law, and document in the medical record". The higher rates of reporting in patients referred from ER as compared to others may be related to seriousness of the matter as viewed by the patients due to ER visit as the rates of counseling were not significantly different between referral categories.

There were a number of potential methodological limitations in our study. We relied solely on patients' statements for information regarding their driving and reporting practices rather than documentation from the TR. We would expect that the direction of this bias would result in an over-estimation of patients' selfreporting to the TR and an under-estimation of illegal driving practices. Future studies in North America in which patients' selfreporting behaviors are linked with a TR database could potentially address this methodological concern. Another limitation of our study is derived from the fact that it was performed at a single center in a discretionary reporting province in Canada. These results are therefore not generalizable to provinces in the country that have mandatory physician reporting structures (e.g. Ontario), but are more pertinent to the majority of jurisdictions in North America as well as the rest of the world that have similar reporting structures as Alberta. Lastly, the relevance of our study's findings to jurisdictions with vastly different public transportation services than ours is not clear, and future studies wherein patients' work or home geographical proximity to public transportation are measured confounders could be of interest.

\section{CONCLUSIONS AND RECOMMENDATIONS}

Our study makes three points clear in a North American discretionary physician reporting jurisdiction: (1) patients referred to a seizure clinic are very rarely counseled by non-neurologist physicians about their duty to self-report to TRs; (2) even when patients are counseled about self-reporting laws, their disclosure to TRs remains far from complete; (3) patients' compliance with self-reporting laws appears poorer than their compliance with driving restrictions.

We recommend enhanced physician education about driver fitness assessments of seizure as well as non-seizure patients at all levels of physician training. Physicians need to be aware that counseling about driver fitness includes physicians relating accurate information about local laws, and that in the absence of this information, patients and their physicians could face adverse (including legal) consequences.

\section{ACKNOWLEDGEMENTS}

The authors thank Nola Geortz (Registered Nurse, Seizure Clinic, University of Alberta) who made this study possible by administering the questionnaires, and Dr. Donald Gross for his thoughtful comments regarding the manuscript.

\section{CONFLICTS OF INTEREST}

The authors do not have any conflicts of interest to declare.

\section{DisCLOSURES}

The authors do not have anything to disclose

\section{REFERENCES}

1. Redelmeier DA, Yarnell CJ, Thiruchelvam D, Tibshirani RJ. Physicians' warnings for unfit drivers and the risk of trauma from road crashes. N Engl J Med. 2012;367:1228-36.

2. Redelmeier DA, Vinkatesh V, Stanbrook MB. Mandatory reporting by physicians of patients potentially unfit to drive. Open Med. 2008;2:e8-17.

3. McLachlan RS, Starreveld E, Lee MA. Impact of mandatory physician reporting on accident risk in epilepsy. Epilepsia. 2007;48:1500-5.

4. Phemister JC. Epilepsy and car-driving. Lancet. 1961;1:1276-7.

5. Maxwell RDH, Leyshon GE. Epilepsy and driving. BMJ. 1971;3:12-5.

6. van der Lugt PJ. Is an application form useful to select patients with epilepsy who may drive? Epilepsia. 1975;16:743-6.

7. Edeh J. Epilepsy and driving. Lancet. 1985;2:1014.

8. Dickey W, Morro JI. Epilepsy and driving: attitudes and practices among patients attending a seizure clinic. J Royal Soc Med. 1993;88:566-8

9. Dalrymple J, Appleby J. Cross sectional study of reporting of epileptic seizures to general practitioners. BMJ. 2000;320:94-7.

10. Salinsky MC, Wegener K, Sinnema F. Epilepsy, driving laws, and patient disclosure to physicians. Epilepsia. 1992;33:469-72. 
11. Taylor J, Chadwick DW, Johnson T. Accident frequency and notification rates in people with recent seizures, epilepsy or undiagnosed episodes of loss of consciousness. Q J Med. 1995;88:733-40.

12. http://www.transportation.alberta.ca/content/docType45/Production/ CCMTADriverMedicalStandardsAugust2013.pdf December 11, 2013.

13. http://www.cma.ca/multimedia/CMA/pdf/CMA-Drivers-Guide-8thedition-e.pdf June 8, 2014.

14. http://www.qp.alberta.ca/documents/acts/t06.pdf June 8, 2014.

15. Bornemann MT. View-point of a driver with epilepsy. Epilepsia. 1994;35:665-7.

16. Gilliam F, Kuzniecky R, Faught E, Black L, Carpenter G, Schrodt R. Patient-validated content of epilepsy-specific quality-of-life measurement. Epilepsia. 1997;38:233-6.

17. Maas R, Ventura R, Kretzschmar C, Aydin A, Schuchert A. Syncope, driving recommendations and clinical reality. BMJ. 2003;325: 21-2.

18. Quaglieri CE. Physician responsibility for epileptics' compliance with motor vehicle laws. J Leg Med (N Y). 1977;5:8AA-BB.

19. Selmo KK, Asp DS, Anderson DC. Seizures and spells: physicians' awareness of Minnesota driving laws. Minn Med. 1997;80: 42-6.
20. Turnipseed SD, Vierra D, DeCarlo D, Panacek EA. Reporting patterns for "lapses of consciousness" by California emergency physicians. J Emerg Med. 2008;35:15-21.

21. Andermann F, Remillard GM, Zifkin BG, Trottier AG, Drouin P. Epilepsy and driving. Can J Neurol Sci. 1988;15:371-7.

\section{Appendix 1: Seizure Clinic Driving Questionnaire}

1) Do you hold a valid driver's license?

2) What is the date of your most recent spell?

3) Prior to this recent spell, did you routinely drive a motor vehicle?

4) Have you been driving a motor vehicle since the spell which prompted this referral?

5) Have you been told by a medical professional prior to this visit not to drive?

6) Have you been told by a medical professional prior to this visit to self-report your medical condition to the Ministry of Transportation?

7) Have you notified the Ministry of Transportation of your condition? 